\title{
Knowledge and Perceptions of Environmental Issues by African Americans/Blacks in Washington, DC, USA: Giving Voice to the Voiceless
}

\author{
Elgloria Harrison ${ }^{1,2}, * \mathbb{( D}$, Ashley D. Milton ${ }^{2,3}$ and Matthew L. Richardson ${ }^{2}(\mathbb{0})$ \\ 1 School of Health Sciences, Human Services, and Nursing, Lehman College City University of New York, \\ Bronx, NY 10468, USA \\ 2 College of Agriculture, Urban Sustainability and Environmental Sciences, University of the District of Columbia, \\ Washington, DC 20008, USA; ashley@shegrowsit.com (A.D.M.); matthew.richardson@udc.edu (M.L.R.) \\ 3 She Grows It ${ }^{\mathrm{TM}}$, Washington, DC 20032, USA \\ * Correspondence: elgloria.harrison@lehman.cuny.edu
}

Received: 25 September 2020; Accepted: 11 November 2020; Published: 15 November 2020

\begin{abstract}
Our study elucidated knowledge and perceptions of natural resources and climate change by African Americans/Blacks in Washington, DC since they are a traditionally marginalized population and to see if we could dispel the perception that they have low knowledge and interest in environmental issues. Secondarily, we wanted to determine if knowledge and perceptions vary across age groups. We conducted a survey of 491 Blacks in the District and asked 26 questions/statements related to natural resources, climate change, economics, and health. Participants were categorized into four age groups 18-25, 26-40, 41-65, and 66 and older for analysis. We found that the level of environmental knowledge across the age groups was relatively high and largely similar. Our results suggest that Blacks care about the environment, see the environment as beneficial to their health, and are knowledgeable about natural resources. However, younger Blacks (18-25) were the least likely to think of the natural world as a community to which they belong, report feelings of connection to it, and recognize that it impacts their personal welfare. In conclusion, we find that Blacks in the District possess environmental awareness and use local environmental language, depicting the uniqueness of their community. The mainstream environmental movement may fail to recognize this local language, leading to exclusion of vulnerable populations based on a faulty premise that these populations lack knowledge or interest in environmental issues.
\end{abstract}

Keywords: age; climate change; District of Columbia; environmental justice; natural resources

\section{Introduction}

Knowledge and perceptions of natural resources and climate change terms, decisions and policies among underrepresented minorities, including people of color, has received little attention in the literature. Policy decisions on natural resources and access to natural resources are rarely inclusive of these communities. For example, non-Hispanic Black communities experience the poorest air quality [1] and green spaces are inadequate in low income neighborhoods [2,3]. Moreover, African Americans/Blacks (hereafter "Blacks") were exposed to a higher rate of toxic water pollutants in Flint, Michigan, USA than other racial groups [4,5]. The environmental justice movement centers on environmental hazards that have impacted minority communities far more often than whites [1]; however, perceptions of Blacks about issues like natural resources and climate change are not well understood. There is a need to strengthen environmental justice research by including areas with limited scholarship to date [6]. Our current research is an expansion of the environmental justice 
framework by applying the social equity lens to understand knowledge and perceptions of Blacks in Washington, DC. Social equity is defined as "the fair, just, and equitable management of all institutions serving the public directly" [2]. We believe our research presents a perspective on knowledge and perceptions that perhaps is unique within minority populations. Our research also highlights some challenges facing Blacks in general and DC in particular that are related to environmental justice issues.

Previous research investigating links between demographics and environmental behaviors and attitudes is sometimes incongruent. One study found differences in pro-environmental behaviors due to age, education, urban living, political ideology, and race/ethnicity [7]. In this study, one of the most prominent findings revealed that Blacks maintain lower pro-environmental behaviors than other racial/ethnic groups when measured with mainstream environmental activities of the dominant culture but suggest that including environmental justice issues embraced by the Black community may more accurately reflect their pro-environmental behavior [7]. Other studies found either nonsignificant differences between whites and Blacks or found that the latter have higher pro-environmental behaviors and attitudes [8,9], showed that youth had high pro-environmental behaviors [7,10], and that immigrants demonstrated higher pro-environmental behaviors [11]. Moreover, a group of researchers reported an under-estimation of environmental concerns among minority and low-income Americans [8]. Despite these findings, the public perceives that if you are white and affluent you are more likely to be an environmentalist, but if you are minority or low income you are less concerned about environmental issues [8].

The environmental justice lens provides a framework to evaluate social inequities among racial and ethnic groups, which often have profound negative consequences such as exposure to poor air quality that exacerbates asthma or exposure to toxic water pollutants [4,5]. Environmental justice has been traditionally framed as disproportionate exposure of minorities and people of color to environmental hazards and pollution that are located on inexpensive land near communities that are least likely to raise resistance to the environmental polluters $[4,12]$, but should also include equitable access to resources in order to sustain a healthy lifestyle and inclusivity when making decisions that impact a community. Sheppard pointed out that, while on the surface there seem to be differences in environmental positions of Blacks and whites, there is a multi-complexity within the everyday lives of Blacks [9]. It is not that Blacks are less concerned about environmental issues, it is that they may prioritize environmental issues that have a more negative impact on their health and wellbeing $[9,13]$.

Climate change is currently the greatest environmental problem worldwide and disproportionately has a negative impact on underrepresented minorities and people of color [14]. Much of the debate on climate change is centered around implementing policy and actions that will help society adapt (i.e., adjust) to it or mitigate it (i.e., reduce or eliminate the causes). Conversations around adaptation and mitigation can be highly technical, which begs the question about whether the average person is able to understand the concept of climate change and its implications for individuals, families or communities. Moreover, residents who have low literacy levels or are uneducated or undereducated may have less understanding of these concepts than those with advanced education [15]. A derivative of environmental justice that recognizes and responds to the injustices of climate change on certain communities is climate justice. The climate justice movement grew out of the development of the Climate Justice Action network, which defined the concept as "moving to a post-carbon energy system, paying for the ecological and social damage of climate change, and protecting the voice and sovereignty of the most vulnerable" [16]. The concept of climate justice highlighted these issues at the grassroots level where impacts are felt, vulnerabilities are spotlighted, and community voices can be heard [16]. The need for this grassroots movement was realized after disasters such as Hurricane Katrina, which was a calamity that decimated Black communities in New Orleans (LA, USA). The long-term fall-out from social and environmental injustices that were brought to the fore by Hurricane Katrina are still evident 15 years after this disaster [16].

There is the perception, which is likely a misconception, that Blacks have less interest in the environment, including natural resources and climate change, than whites [17]. However, 
this perception may be the function of the environmental movement being led primarily by white leaders, research being published by predominantly white academia, a feeling of powerlessness of the minority community and differences in cultural expression $[18,19]$. For example, a study with Blacks and whites demonstrated that environmentalism is evident in both groups, but displayed in different ways. For example, Blacks showed higher interest in issues such as litter, fresh water and air pollution, whereas whites were more interested in overpopulation [19]. This research further suggests that it is natural for Blacks to be concerned about urban environmental issues as they are often the main residents in communities where these issues are most prevalent [19]. The environmental and climate justice movements spurred grassroot activism among Blacks even when odds were against them [20,21], so this counters the notion that Blacks are less interested in environmental issues. Blacks that live in coastal communities are aware of the environmental devastation of flooding in their communities [22], and we see these community stakeholders engaged in environmental decision-making to minimize the risk of flooding. Moreover, a study found that Black youth in impoverished neighborhoods recognize the social inequity of environmental hazards in their neighborhood and the impact on their health and wellbeing [23]. Knowledge learned from focus groups of these Black youths was able to help map environmental inequities across many Pittsburgh communities [23]. However, Blacks are still often excluded from discussions about natural resources and climate change, so it is important to determine their knowledge and perceptions of natural resources and climate change and perhaps some of the underlying reasons they are viewed as being less interested in the environment.

Knowledge and perceptions about natural resources and climate change may vary due to other demographic characteristics beyond race. For example, those with more education may have more environmental knowledge and place more emphasis on global environmental issues than those with less education [15]. Age may also play a role, but knowledge and pro-environmental behavior are often hard to predict based on age. In some cases, older adults have a greater connection and concern about nature [24], but in others pro-environmental behaviors were demonstrated more in younger people [25]. Research has found pro-environmental behaviors and participation in eco-tourism among students in Australia [26] and active participation of youth in environmental and social justice work [27], which suggests that young people may add an additional dimension to environmentalism. Since not as much research has been done on Blacks, it is less clear about how other demographic variables may influence their knowledge and perceptions of environmental issues. Our interest in understanding what Blacks know and perceive falls within the environmental justice umbrella. We further believe that natural resources, participation in environmental decision-making and climate impacts are distributed unequally in minority and low-income communities [8,13].

We previously surveyed residents in each of the eight Wards in Washington, DC (Wards are geographic divisions of the District; each ward represents approximately 75,000 people) and found that what people knew and perceived about natural resources and climate change varied based on their educational level [15]. In that study we sampled Blacks more heavily than other racial groups, but they were not the focus. In this paper we used responses from the Black participants in our previous publication [15] and expanded our sampling of Blacks to: (1) elucidate knowledge and perceptions of natural resources and climate change by Blacks only since they are a traditionally marginalized population and to see if we could dispel the perception that they have less knowledge and interest in environmental issues; and (2) determine if knowledge and perceptions vary across age groups.

\section{Materials and Methods}

We collected demographic information (i.e., age, education, ethnicity, gender, and place of primary residence) and responses to 24 open-ended, closed-ended and Likert scale questions/statements (hereafter "questions") to assess knowledge and perceptions of Black participants. The questions came from a survey tool we previously developed [15] and some originally appeared on the connectedness-to-nature-scale [28]. 
The survey was distributed in two ways: through face-to-face interviews conducted by undergraduate students in our classes at the University of the District of Columbia and online by Qualtrics (Provo, UT, USA). Face-to-face surveys focused on 11 different neighborhoods in Washington, DC. For face-to-face interviews students read the questions from, and inputted answers into, the iSurvey app (Harvest Your Data, Wellington, New Zealand). Interviews were conducted during each fall semester from 2016-2018. Participants were recruited largely along sidewalks, but also at transit stations, businesses, libraries and homes. All participants were adults ( $\geq 18$ years old) and were selected because they were the first ones encountered in an area. A survey was considered complete once a participant was read the final question, but it was optional to answer each question. In spring 2020, Qualtrics validated the online survey tool and recruited Black participants from market research panels in Washington, DC's eight Wards. Qualtrics presents surveys in a dashboard style where potential participants receive an invitation for surveys for which they qualify. Participants complete the survey by accepting the invitation, clicking a link and moving through all questions. The number of participants reached were: 324 through interviews and 167 through the online survey (total $n=491$ ). Approximately $52 \%$ and $48 \%$ of the participants identified as female and male, respectively, which aligns well with the overall population in Washington, DC (Table 1). Sample size for 20 questions was 491 but was 490 for two Likert scale questions and 418 and 451 for two open-ended questions when some participants opted not to respond to these four questions.

Table 1. Demographics of African Americans/Blacks surveyed in Washington, DC, USA compared to DC's population of Blacks in 2020 [29].

\begin{tabular}{|c|c|c|}
\hline & Survey $(n=491)$ & DC Census \\
\hline \multirow{2}{*}{ Gender } & Female $255(52 \%)$ & $376,379(52.5 \%)$ \\
\hline & Male $236(48 \%)$ & $340,810(47.5 \%)$ \\
\hline \multirow{4}{*}{ Age } & $18-25139$ (28\%) & $\begin{array}{l}18-2032,047(4.5 \%) \\
21-2434,934(4.9 \%)\end{array}$ \\
\hline & $26-40144(29 \%)$ & $\begin{array}{l}25-34161,499(22.5 \%) \\
35-44109,063(15.2 \%)\end{array}$ \\
\hline & $41-65171(35 \%)$ & $\begin{array}{c}45-5479,733(11.1 \%) \\
55-6472,010(10 \%)\end{array}$ \\
\hline & $>6537(8 \%)$ & $\begin{array}{c}65-7453,567(7.5 \%) \\
75-84 \text { 26,149 (3.7\%) } \\
\geq 8511,904(1.7 \%)\end{array}$ \\
\hline
\end{tabular}

Participants were categorized into one of four age groups to see if knowledge and perceptions varied among them: (1) 18-25 years old $(n=139)$; (2) 26-40 years old $(n=144)$; (3) 41-65 years old $(n=171)$; and (4) over 65 years old $(n=37)$ (Table 1$)$. Whereas we used four age groups, the DC population census uses more age groups with a smaller range. The age distribution of survey participants was less representative than the DC population of Blacks (Table 1). We did not further separate age groups based on other demographic structure (i.e., education, ethnicity, gender, and place of residence) because the resulting sample size would have prohibited meaningful analyses.

Four open-ended questions probed participants' knowledge and perceptions of natural resources (Table 2). We coded answers to these questions to categorize responses and then analyzed the number of participants selecting each response category with $\chi^{2}$ contingency tests to determine whether responses differed among age groups. We used the open-ended questions, "Can you describe what natural resources are?" and "Can you describe what climate change is to you" to determine whether participants could or could not describe natural resources and climate change, so Table 2 gives the percentages after coding answers to "yes" or "no." Answers to the question "What do you consider to be the most important natural resource?" were coded into five categories: air, energy, water, multiple resources (when more than one resource was named) and other (for infrequently mentioned natural 
resources and resources that were not natural). Answers to the question "Which natural resources have been threatened the most in your neighborhood?" were coded into six categories: air, plants, water, multiple resources, other and none (when a participant said that resources were not threatened).

Table 2. Open-ended questions that assessed knowledge and perceptions of African Americans/Blacks in Washington, DC, USA about the interconnectedness of natural resources, climate change, economics and socio-cultural well-being.

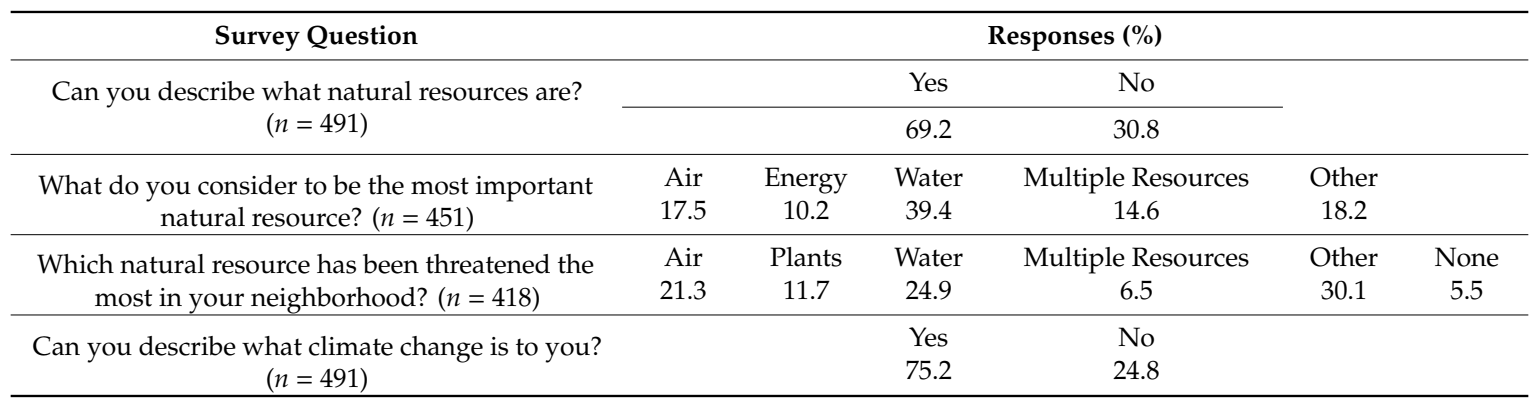

We also used separate $\chi^{2}$ contingency tests to determine whether the number of responses to the other 20 questions differed among age groups. One of these questions assessed what people thought about spending by District government for natural resources versus other priority areas such as health, workforce development, education, protecting natural resources, developing natural resources, law enforcement and drug rehabilitation (Table 3). Responses for each of the 24 questions are presented as percentages in Tables for ease of interpretation of data. Responses are divided by age group in the Tables only when statistically significant $(p<0.05)$ to simplify presentation of data. Actual and expected counts for questions that had different responses across age groups are presented in Table S1. 
Table 3. Closed-ended and Likert scale questions/statements that assessed knowledge and perceptions of African Americans/Blacks in Washington, DC, USA about the interconnectedness of natural resources, climate change, economics and socio-cultural well-being. Responses are categorized by age and statistical results are given when this demographic variable was significant.

\begin{tabular}{|c|c|c|c|c|c|c|c|}
\hline \multirow{2}{*}{$\begin{array}{c}\text { Survey Question/Statement } \\
\text { I have a strong knowledge of natural resources. }\end{array}$} & \multirow{2}{*}{$\frac{\text { Age (Sample Size) }}{\text { N/A }}$} & \multicolumn{5}{|c|}{ Responses (\%) } & \multirow{2}{*}{$\frac{\text { Statistic }}{\mathrm{N} / \mathrm{A}}$} \\
\hline & & $\begin{array}{l}\text { Strongly disagree } \\
5.9\end{array}$ & $\begin{array}{l}\text { Somewhat disagree } \\
12\end{array}$ & $\begin{array}{c}\text { Neutral } \\
38.9\end{array}$ & $\begin{array}{c}\text { Somewhat agree } \\
22.4\end{array}$ & $\begin{array}{l}\text { Strongly agree } \\
20.8\end{array}$ & \\
\hline \multirow[t]{5}{*}{$\begin{array}{l}\text { I think of the natural world as a community to } \\
\text { which I belong. }\end{array}$} & & Strongly disagree & Somewhat disagree & Neutral & Somewhat agree & Strongly agree & $\begin{array}{c}\chi^{2}=29.2 \\
\mathrm{df}=12 \\
p=0.004\end{array}$ \\
\hline & 18-25 (139) & 2.9 & 12.9 & 38.1 & 18.7 & 27.3 & \\
\hline & $26-40(144)$ & 5.6 & 3.5 & 25 & 31.9 & 34 & \\
\hline & $41-65(171)$ & 3.5 & 5.3 & 27.5 & 21.6 & 42.1 & \\
\hline & $>65$ (37) & 0 & 8.1 & 24.3 & 27 & 40.5 & \\
\hline \multirow[t]{5}{*}{ I often feel disconnected from nature. } & & Strongly disagree & Somewhat disagree & Neutral & Somewhat agree & Strongly agree & $\begin{array}{c}\chi^{2}=35.1 \\
\mathrm{df}=12 \\
p<0.001\end{array}$ \\
\hline & 18-25 (139) & 13.7 & 18.7 & 30.9 & 21.6 & 15.1 & \\
\hline & $26-40$ (144) & 20.1 & 27.8 & 20.1 & 18.1 & 13.9 & \\
\hline & $41-65(171)$ & 29.8 & 27.5 & 17.5 & 9.9 & 15.2 & \\
\hline & $>65$ (37) & 35.1 & 18.9 & 8.1 & 27 & 10.8 & \\
\hline \multirow[t]{5}{*}{$\begin{array}{l}\text { My personal welfare is not connected to the } \\
\text { welfare of the natural world. }\end{array}$} & & Strongly disagree & Somewhat disagree & Neutral & Somewhat agree & Strongly agree & $\begin{array}{c}\chi^{2}=41.3 \\
\mathrm{df}=12 \\
p<0.001\end{array}$ \\
\hline & $18-25$ (139) & 11.5 & 23.7 & 35.3 & 19.4 & 10.1 & \\
\hline & $26-40(144)$ & 20.8 & 27.8 & 25.7 & 14.6 & 11.1 & \\
\hline & $41-65(171)$ & 35.1 & 17.5 & 26.9 & 10.5 & 9.9 & \\
\hline & $>65(37)$ & 40.5 & 18.9 & 8.1 & 16.2 & 16.2 & \\
\hline \multirow[t]{2}{*}{$\begin{array}{c}\text { Human activities have little influence on } \\
\text { natural resources. }\end{array}$} & N/A & Strongly disagree & Somewhat disagree & Neutral & Somewhat agree & Strongly agree & N/A \\
\hline & & 34.6 & 18.7 & 16.5 & 12 & 18.1 & \\
\hline \multirow{2}{*}{$\begin{array}{l}\text { Technological advances will ensure that we do } \\
\text { not make the earth unlivable. }\end{array}$} & N/A & Strongly disagree & Somewhat disagree & Neutral & Somewhat agree & Strongly agree & N/A \\
\hline & & 14.1 & 19.3 & 33 & 18.5 & 15.1 & \\
\hline Humans are severely abusing the environment. & N/A & $\begin{array}{l}\text { Strongly disagree } \\
4.3\end{array}$ & $\begin{array}{l}\text { Somewhat disagree } \\
5.5\end{array}$ & $\begin{array}{c}\text { Neutral } \\
15.1\end{array}$ & $\begin{array}{c}\text { Somewhat agree } \\
25.5\end{array}$ & $\begin{array}{c}\text { Strongly agree } \\
49.7\end{array}$ & N/A \\
\hline \multirow{2}{*}{$\begin{array}{l}\text { Local environmental concerns are more } \\
\text { important than global environmental concerns. }\end{array}$} & N/A & Strongly disagree & Somewhat disagree & Neutral & Somewhat agree & Strongly agree & N/A \\
\hline & & 12.6 & 20.6 & 35.2 & 16.9 & 14.7 & \\
\hline
\end{tabular}


Table 3. Cont

\begin{tabular}{|c|c|c|c|c|c|c|c|c|}
\hline \multirow{3}{*}{$\begin{array}{c}\text { Survey Question/Statement } \\
\begin{array}{c}\text { The natural resources in your neighborhood } \\
\text { cannot support more people. }\end{array}\end{array}$} & \multirow{3}{*}{$\frac{\text { Age (Sample Size) }}{\text { N/A }}$} & \multicolumn{6}{|c|}{ Responses (\%) } & \multirow{3}{*}{$\frac{\text { Statistic }}{\text { N/A }}$} \\
\hline & & Strongly disagree & Somewhat disagree & Neutral & Somewhat agree & Strongly agree & & \\
\hline & & 6.5 & 20 & 37.5 & 21.4 & 14.7 & & \\
\hline \multirow{2}{*}{$\begin{array}{l}\text { The earth has plenty of natural resources if we } \\
\text { just learn how to develop them. }\end{array}$} & N/A & Strongly disagree & Somewhat disagree & Neutral & Somewhat agree & Strongly agree & & N/A \\
\hline & & 5.1 & 11 & 22.9 & 27.5 & 33.5 & & \\
\hline \multirow{2}{*}{$\begin{array}{l}\text { Humans will eventually learn enough about } \\
\text { how nature works to be able to control it. }\end{array}$} & N/A & Strongly disagree & Somewhat disagree & Neutral & Somewhat agree & Strongly agree & & N/A \\
\hline & & 12.2 & 21.6 & 25.5 & 22.6 & 18.1 & & \\
\hline \multirow{2}{*}{$\begin{array}{l}\text { If things continue on their present course, } \\
\text { we will soon experience an } \\
\text { environmental catastrophe. }\end{array}$} & N/A & Strongly disagree & Somewhat disagree & Neutral & Somewhat agree & Strongly agree & & N/A \\
\hline & & 4.3 & 5.5 & 23.4 & 26.1 & 40.7 & & \\
\hline \multirow{2}{*}{$\begin{array}{l}\text { There is too much worry about natural } \\
\text { resources and not enough about jobs. }\end{array}$} & & Strongly disagree & Somewhat disagree & Neutral & Somewhat agree & Strongly agree & & N/A \\
\hline & N/A & 15.3 & 24.8 & 28.1 & 14.7 & 17.1 & & \\
\hline \multirow{2}{*}{$\begin{array}{l}\text { Natural resources in my neighborhood } \\
\text { are plentiful. }\end{array}$} & & Strongly disagree & Somewhat disagree & Neutral & Somewhat agree & Strongly agree & & N/A \\
\hline & N/A & 10.6 & 22.6 & 37.1 & 17.1 & 12.6 & & \\
\hline \multirow{2}{*}{$\begin{array}{l}\text { Climate change has a negative impact on } \\
\text { natural resources in my neighborhood. }\end{array}$} & N/A & Strongly disagree & Somewhat disagree & Neutral & Somewhat agree & Strongly agree & & N/A \\
\hline & & 4.5 & 9.4 & 32.2 & 26.1 & 27.9 & & \\
\hline \multirow{2}{*}{$\begin{array}{l}\text { I understand that the natural environment } \\
\text { impacts my individual health. }\end{array}$} & & Strongly disagree & Somewhat disagree & Neutral & Somewhat agree & Strongly agree & & $\mathrm{N} / \mathrm{A}$ \\
\hline & N/A & 1.8 & 3.3 & 20 & 28.1 & 46.8 & & \\
\hline \multirow{2}{*}{$\begin{array}{c}\text { Degraded natural resources in my } \\
\text { neighborhood have a negative impact on (select } \\
\text { all that apply): }\end{array}$} & & $\begin{array}{l}\text { you or your } \\
\text { family's income }\end{array}$ & $\begin{array}{l}\text { you or your } \\
\text { family's health }\end{array}$ & $\begin{array}{l}\text { other parts of the } \\
\text { local environment }\end{array}$ & $\begin{array}{l}\text { your cultural or } \\
\text { social practices }\end{array}$ & $\begin{array}{l}\text { the aesthetics of the } \\
\text { neighborhood }\end{array}$ & $\begin{array}{c}\text { your } \\
\text { recreation }\end{array}$ & \\
\hline & $\mathrm{N} / \mathrm{A}$ & 24.6 & 60.9 & 55.6 & 30.1 & 36.5 & 35 & N/A \\
\hline \multirow[t]{2}{*}{$\begin{array}{l}\text { Which people or groups do you think have the } \\
\text { most responsibility for improving natural } \\
\text { resources in your neighborhood? }\end{array}$} & & Individuals & $\begin{array}{l}\text { Community } \\
\text { organizations }\end{array}$ & Businesses & $\begin{array}{l}\text { Environmental } \\
\text { groups }\end{array}$ & District government & $\begin{array}{c}\text { Federal } \\
\text { government }\end{array}$ & \\
\hline & N/A & 37.3 & 5.9 & 6.7 & 7.8 & 14.1 & 28.2 & N/A \\
\hline \multirow[t]{2}{*}{$\begin{array}{l}\text { How often do you spend time doing } \\
\text { outdoor activities? }\end{array}$} & & Never & $\begin{array}{l}\text { Very infrequently } \\
\text { (once a week) }\end{array}$ & $\begin{array}{c}\text { Occasionally } \\
\text { (3 days a week) }\end{array}$ & $\begin{array}{c}\text { Frequently } \\
\text { (5 days a week) }\end{array}$ & $\begin{array}{c}\text { Almost daily } \\
\text { (>5 days a week) }\end{array}$ & & \\
\hline & N/A & 3.5 & 17.3 & 29.3 & 21.2 & 28.7 & & N/A \\
\hline
\end{tabular}




\section{Results}

Participants across the four age groups answered 20 of 24 questions similarly, including all four open-ended questions. Approximately $69 \%$ and $75 \%$ of participants were able to describe natural resources and climate change, respectively (Table 2). Participants most frequently mentioned water as the most important natural resource and the one most threatened in their neighborhood, but there was large variance in responses (Table 2).

Responses to 16 close-ended and Likert scale questions were answered similarly across age groups (results supporting this paragraph are in Table 3). Half the participants reported spending time outdoors frequently ( 5 days per week) or almost daily. Despite participants demonstrating that they could describe natural resources, fewer than $44 \%$ somewhat or strongly agreed that they have a strong knowledge of natural resources. More than half the participants somewhat or strongly disagreed that human activities have little influence on natural resources and 75\% somewhat or strongly agreed that humans are severely abusing the environment. Furthermore, 61\% somewhat or strongly agreed that earth has plenty of natural resources if we learn how to develop them, but approximately $67 \%$ somewhat or strongly agreed that if things continue on their present course, we will soon experience an environmental catastrophe. More than half also somewhat or strongly agreed that climate change has a negative impact on natural resources in their neighborhood, indicated that they understand that the natural environment impacts their individual health and that degraded natural resources in their neighborhood have a negative impact on their personal health or their family's health and other parts of the local environment. There was no consensus about whether technological advances will ensure that we do not make the earth unlivable, that local environmental concerns are more important than global concerns, that natural resources in their neighborhood cannot support more people, that humans will eventually learn enough about how nature works to be able to control it, that there is too much worry about natural resources and not enough about jobs, and that natural resources in their neighborhood are plentiful. The most common response was neutral for these six questions and the percentages between those agreeing and disagreeing was similar. There was also no consensus about which people or groups participants thought had the most responsibility for improving natural resources in their neighborhood, with individuals being selected most frequently (37.3\% of participants) followed by federal government (28.2\%) and District government (14.1\%). Community organizations, businesses and environmental groups were less frequently selected (all by fewer than $8 \%$ of participants).

The question that assessed what people thought about spending by District government found that people of all ages agreed about spending for health, workforce development, protecting natural resources and developing natural resources (Table 4). More than half said that District government spends too little on health and workforce development. Approximately half said that District government spends about the right amount on protecting and developing natural resources. Few participants thought spending was too much for any of these priority areas.

In the three Likert scale questions that had different responses due to age (Table 3), the youngest age group (18-25 years old) was most different from the others. They were the least likely to somewhat or strongly agree that they think of the natural world as a community to which they belong (46\% versus $63.7-67.5 \%$ of other participants). They were also the least likely to somewhat or strongly disagree that they often feel disconnected from nature (35.2\% versus $48.6-59.4 \%$ of other participants) and that their personal welfare is not connected to the welfare of the natural world $(35.2 \%$ versus $59.4 \%$ of other participants).

The question that assessed what people thought about spending by District government found that responses varied across age groups for education, law enforcement and drug rehabilitation (Table 4). In the latter two cases there was a clear association between the responses and age: the oldest age group was most likely to say that District government spent too little on these priority areas and the percentages of participants agreeing with this question decreased with decreasing age. The reverse trend was also true: the oldest age group was least likely to say that District government spent too much on these priority areas and the percentages of participants agreeing with this question increased with 
age. However, there was not a linear correlation between age and spending on education. The oldest three age groups were more likely than the youngest age group to say that spending on education was too little.

Table 4. Responses of 491 African Americans/Blacks in Washington, DC, USA when asked "For each of the following categories, answer whether you think the District government is spending too little, about the right amount, too much, undecided." Responses are categorized by age and statistical results are given when this demographic variable was significant.

\begin{tabular}{|c|c|c|c|c|c|c|}
\hline Category & Age (Sample Size) & & & Responses $(\%$ & & \\
\hline & & Too Little & $\begin{array}{c}\text { About the Right } \\
\text { Amount }\end{array}$ & Too Much & Undecided & Statistics \\
\hline Health & N/A & 56.2 & 28.3 & 5.9 & 9.6 & N/A \\
\hline Workforce development & N/A & 50.3 & 33.2 & 4.5 & 12 & N/A \\
\hline Education & $\begin{array}{c}18-25(139) \\
26-40(144) \\
41-65(171) \\
>65(37)\end{array}$ & $\begin{array}{l}49.6 \\
63.9 \\
60.2 \\
59.5\end{array}$ & $\begin{array}{c}33.8 \\
25.0 \\
30.4 \\
27\end{array}$ & $\begin{array}{l}7.9 \\
7.6 \\
1.2 \\
5.4 \\
\end{array}$ & $\begin{array}{l}8.6 \\
3.4 \\
8.2 \\
8.1\end{array}$ & $\begin{array}{c}\chi^{2}=44.3 \\
\mathrm{df}=9 \\
p<0.001\end{array}$ \\
\hline Protecting natural resources & N/A & 25.7 & 55.8 & 4.5 & 14.1 & N/A \\
\hline $\begin{array}{l}\text { Developing natural } \\
\text { resources }\end{array}$ & N/A & 26.7 & 48.7 & 8.6 & 16.1 & N/A \\
\hline Law enforcement & $\begin{array}{c}18-25(139) \\
26-40(144) \\
41-65(171) \\
>65(37)\end{array}$ & $\begin{array}{l}20.9 \\
28.5 \\
32.2 \\
48.6\end{array}$ & $\begin{array}{l}19.4 \\
29.9 \\
36.3 \\
29.7\end{array}$ & $\begin{array}{l}46.8 \\
31.9 \\
20.5 \\
10.8\end{array}$ & $\begin{array}{c}12.9 \\
9.7 \\
11.1 \\
10.8\end{array}$ & $\begin{array}{c}x^{2}=44.3 \\
\mathrm{df}=9 \\
p<0.001\end{array}$ \\
\hline Drug rehabilitation & $\begin{array}{c}18-25(139) \\
26-40(144) \\
41-65(171) \\
>65(37)\end{array}$ & $\begin{array}{l}48.2 \\
43.8 \\
57.9 \\
70.3\end{array}$ & $\begin{array}{l}21.6 \\
31.3 \\
22.2 \\
18.9\end{array}$ & $\begin{array}{c}12.9 \\
11.8 \\
5.3 \\
2.7\end{array}$ & $\begin{array}{c}17.3 \\
13.2 \\
14.6 \\
8.1\end{array}$ & $\begin{array}{c}\chi^{2}=23.6 \\
\mathrm{df}=9 \\
p=0.005\end{array}$ \\
\hline
\end{tabular}

\section{Discussion}

Our results contribute to environmental justice through social equity by suggesting that most Blacks in Washington, DC are knowledgeable about environmental issues. Blacks have a long historical relationship with nature that dates back 400 years in the United States [10]. Underscoring the historical acknowledgment to the period of slavery brings emphasis on why Black culture matters. Blacks usually did not come willingly to this country, but came as a commodity, unlike other minority groups who arrived in America to pursue economic prosperity [30]. Perhaps knowledge about nature has been shaped by the environmental experiences of Blacks as one of survival rather than of solace. Blacks may have been perceived as being indifferent to mainstream environmental issues because many lack involvement in mainstream environmental organizations compared to whites. However, Blacks have been at the forefront of the environmental justice movement by advocating for justice on local issues that negatively impact their communities $[4,13,16,31,32]$.

Unexpectedly, our analysis showed largely similar levels of knowledge and perception across the four different age groups. However, the differences we did find were driven by younger Blacks (18-25) in comparison to all others ( 26 and older). Young Black adults ages 18-25 have their own set of struggles. We know that $18 \%$ of this age group are not high school graduates [33] and many grew up in single female heads of households, below the poverty line and were the dominant group at underperforming schools in the District $[33,34]$. They may have some environmental literacy, but perhaps there are far more pressing issues facing this group such as over-policing and police brutality, which could explain why nearly half this group responded that the District is spending too much on law enforcement.

Given environmental disparities between affluent and predominantly white neighborhoods in north and northwestern Washington, DC and lower-income and predominantly Black neighborhoods in south and southeastern Washington, DC, we were able to determine some environmental knowledge and perceptions of Blacks, which gives insight into what they felt were important environmental issues impacting their communities. In a previous study, Black youth in Pittsburgh, PA were interviewed to 
map neighborhood features that caused environmental inequalities such as poverty, spatial segregation and exposure to environmental hazards, which have been shown to impact quality of life [23]. Neighborhoods in Pittsburgh and Washington, DC are similar in that many poor Blacks tend to cluster in impoverished neighborhoods with limited resources, limited political and social capital and high exposure to environmental hazards [23]. While this research looked at black youth exclusively, our research evaluated Blacks across multiple age groups to understand intergenerational dynamics. We found that age was generally not associated with environmental knowledge and perceptions, but environmental knowledge and perceptions did increase with age across a few questions. Contrary to our findings, another research study found that as age increased, environmental behavior and beliefs decreased [7].

Our research suggests a perspective that is rarely told, which is that Blacks care about their environment, recognize linkages between their environment and health, and possess knowledge about natural resources. For example, our results noted that water and air are important to Blacks in the District and they often identify air and water as the most threatened natural resources in their community. Many Blacks across all age groups noted that individuals are responsible for improving natural resources in their neighborhood and that degraded natural resources negatively affect income, health, cultural or social practice, the aesthetics of the neighborhood and recreational activities, which may suggest a leaning toward pro-environmental behaviors that had not been previously reported. Because many Blacks live in impoverished neighborhoods, it is an undeniable fact that local issues are prioritized, which includes environmental issues in these poorly resourced communities. While many urban cities espouse the notion of promoting healthy city environments, not all citizens share these benefits equally [4]. There appears a limited appetite from many local governments to seek true policy implementation that invest resources in impoverished communities. Our results confirm that many Blacks feel that local DC government spends too little on some crucial programs, such as health, workforce development and education, yet these are the very amenities needed to improve quality of life. However, approximately half of Blacks within all age groups acknowledge that DC's government tries to protect and develop adequate natural resources.

The Blacks in DC in this study demonstrated a positive perception toward the environment, which may influence social behaviors and prompt more blacks to be active leaders in environmental discussions in their local communities [22,35]. Our previous research noted that there is a high level of knowledge in the District due, in part, to high education attainment [15]. It would stand to reason that those who are educated are more environmentally literate and those with less education are not as environmentally literate. However, the idea that Blacks as a group lacked adequate understanding about the environment was not supported by our current study. This insight may, in part, be due to use of language by mainstream environmentalists that is disconnected from the culturally appropriate language used by Blacks to describe their knowledge and perceptions of the environment [36]. The words used by Black participants in the District to describe natural resources are local, depicting the uniqueness of their communities. What is missing in most low-income communities to better engage them in grassroots environmental efforts are the resources and tools, including a shared language, that would prepare communities to avoid environmental disasters. Blacks face the highest impacts from degraded environments, with this community facing a $54 \%$ higher health burden compared to the overall population, which was higher than the health burden of non-white communities overall (28\%) and those living under the poverty line (35\%) [37].

We believe the language used to describe Black neighborhoods and communities is vague, absent of real economic solutions for vulnerable groups, and does not address systemic issues surrounding environmental racism that have been identified by journalists, academicians, and governments alike. The use of stereotypical language to describe Black engagement perhaps runs counter to the daily complexity of the lives of Blacks in impoverished neighborhoods. The Kerner report in the Civil Rights era highlighted a Black population that was excluded from environmental decision-making throughout its history and was reduced to living in neighborhoods that were the sites of environmental hazards [36]. 
These neighborhoods were affordable for many poor Blacks, requiring them to reside alongside life-threatening environmental pollutants, but the eruption of discontent and violent activities can be attributed to the environmental and social inequalities that many poor Blacks faced [37]. The report described a sharp divide: "our nation is moving toward two societies, one Black, one white-separate and unequal" [37]. The Civil Rights era has stark similarities to the current era: demonstrations result from pent-up frustration about the lack of equal opportunities to live a healthy lifestyle akin to what is experienced by most white Americans. Many Blacks still live in less desirable neighborhoods with a majority of renters and limited interest on the part of landlords to upkeep properties. Abandoned buildings and degraded environments invite criminal activities and yet resources to protect these neighborhoods are not enough. Social divisions have been fostered by inequity.

Culture has been defined as a way of life shared by members of a population [38] that fosters shared meanings that translate into cohesive behaviors that become social norms. These social norms are reflected in the population's economic, political, religious and social institutions [38]. Research suggests that Blacks share dual characteristics of collectivism and individualism believed to be a coping mechanism to combat exclusion from participation in the dominant society $[29,39]$. There is ample evidence that Blacks band together when faced with threats to their communities [20]. We believe providing Blacks the tools that promote fairness, justice and equity in public policy is the bedrock within the environmental justice framework. The environment is linked to many of the social determinants of health that defines a healthy community [2], but where ecosystems services are not distributed equally across the population, health disparities result.

Blacks are not "educated" by the system in their ecosystems, nor are they empowered or employed in meaningful ways that afford them to contribute to a system in which they hope to subscribe. Blacks have been a significant part of the District's civic life and identity since the city was first declared the national capital in 1791, yet during the 2010 census the District was one of the most segregated cities in the country, with the eastern half of the city being majority Black residents, and the western half being overwhelmingly white. This brings us back to our theory that the language of the environment is a local phenomenon that directly impacts how Blacks are seen in the ecosystem, how they are engaged in the ecosystem and therefore how they engage in, and relate to, the natural world. Considerations of intergenerational and racially diverse stakeholders and their level of knowledge and perceptions of their environment are critical in developing societies with a goal of optimal health outcomes.

In conclusion, our goal was to elucidate knowledge and perceptions of natural resources and climate change by Blacks since they are a traditionally marginalized population and to see if we could dispel the perception that they have less knowledge and interest in environmental issues. Secondarily, we wanted to determine if knowledge and perceptions vary across age groups. Our study focused exclusively on Blacks in the District and found that many were environmentally literate, had strong knowledge of natural resources and were interested in issues beyond just local issues. Our results did not show large disparities due to age, but younger Blacks felt more of a disconnect from nature. We attribute this finding to generational differences from lived experiences and attainment on Maslow's hierarchy [21,31], where older Blacks felt more connected and stable and could thus appreciate nature. Natural resources and climate change are much discussed topics in the media, whether this is print or social media, and perhaps it is not surprising that many Blacks in Washington, DC have some knowledge of natural resources and climate change. We found that the issues that Blacks care about are often like the foci of mainstream environmentalists and the general population [21]. What we believe is missing in this conversation is environmental language that is culturally appropriate and a necessary and constructive political process of creating enough local awareness and political texture so that a meaningful community voice can be developed, heard and actualized by power to evaluate and participate in the decision-making processes that result in policies that ultimately affect their communities.

There are limitations to our study, including sample size and age distribution. Whereas the gender demographics of the participants are reflective of the Black population in Washington, DC, 
a larger sample size and more representative age distribution would further validate our results. The questions we asked could be more culturally appropriate to capture the language differences within Black communities. Blacks may make references to environmental conditions differently than the majority population, making this a limitation when conducting community-based research. Lastly, we believe that culture plays a role in shaping Blacks' views on environmental issues and perhaps our study should have accounted for the role culture plays in responding to our survey questions. In addition to the quantitative survey, we might also consider conducting focus groups of Blacks in all age groups in each Ward to give voice to their knowledge and perceptions in their local communities.

Supplementary Materials: The following are available online at http://www.mdpi.com/2071-1050/12/22/9495/s1. Table S1: Actual (and expected) counts for survey responses from African Americans/Black in Washington, DC that varied across four age groups.

Author Contributions: Conceptualization, E.H., A.D.M. and M.L.R.; methodology, E.H., A.D.M. and M.L.R.; formal analysis, M.L.R.; investigation, E.H., A.D.M. and M.L.R.; writing-original draft preparation, E.H. and M.L.R.; writing - review and editing, E.H., A.D.M. and M.L.R.; visualization, M.L.R.; project administration, E.H. and M.L.R.; funding acquisition, E.H. All authors have read and agreed to the published version of the manuscript.

Funding: This project was partially funded by USDA Joint Venture Agreement 15-JV-11242306-076 between the USDA Northeast Climate Hub and the University of the District of Columbia.

Acknowledgments: We thank the hundreds of survey participants, the dozens of students who helped interview survey participants, Steven Riskey for verifying our statistical methods, and Caitlin Arlotta, Jennifer Bennett-Mintz, Jenifer Gonzalez and Elizabeth Jewett for facilitating some interview sessions.

Conflicts of Interest: The authors declare no conflict of interest. The funders had no role in the design of the study; in the collection, analyses, or interpretation of data; in the writing of the manuscript; or in the decision to publish the results.

\section{References}

1. Miranda, M.L.; Edwards, S.E.; Keating, M.H.; Paul, C.J. Making the environmental justice grade: The relative burden of air pollution exposure in the United States. Int. J. Environ. Res. Public Health 2011, 8, 1755-1771. [CrossRef] [PubMed]

2. Jennings, V.; Larson, L.; Yun, J. Advancing sustainability through urban green space: Cultural Ecosystem services, equity, and social determinants of health. Int. J. Environ. Res. Public Health 2016, 13, 196. [CrossRef]

3. Wolch, J.R.; Byrne, J.; Newell, J.P. Urban green space, public health, and environmental justice: The challenge of making cities "just green enough". Landsc. Urban Plan. 2014, 125, 234-244. [CrossRef]

4. Rickenbacker, H.; Brown, F.; Bilec, M. Creating environmental consciousness in underserved communities: Implementation and outcomes of community-based environmental justice and air pollution research. Sustain. Cities Soc. 2019, 47, 101473. [CrossRef]

5. Schaider, L.A.; Swetschinski, L.; Campbell, C.; Rudel, R.A. Environmental justice and drinking water quality: Are there socioeconomic disparities in nitrate levels in the U.S. drinking water? Environ. Health 2019, 18, 3. [CrossRef]

6. Chakraborty, J.; Collins, T.W.; Grineski, S.E. Environmental justice research: Contemporary issues and emerging topics. Int. J. Environ. Res. Public Health 2016, 13, 1072. [CrossRef]

7. Johnson, C.Y.; Bowker, J.M.; Cordell, H.K. Ethnic variation in environmental belief and behavior: An examination of the new ecological paradigm in a social psychological context. Environ. Behav. 2004, 36, 157-186. [CrossRef]

8. Pearson, A.R.; Schuldt, J.P.; Romero-Canyas, R.; Ballew, M.T.; Larson-Konar, D. Diverse segments of the US public underestimate the environmental concerns of minority and low-income Americans. Proc. Natl. Acad. Sci. USA 2018, 115, 49. [CrossRef]

9. Sheppard, J.A.C. The Black-White Environmental concern gap: An examination of environmental paradigms. J. Environ. Educ. 1995, 26, 24-35. [CrossRef]

10. Heo, J.; Muralidharan, S. What triggers young millennials to purchase eco-friendly products? The interrelationships among knowledge, perceived consumer effectiveness, and environmental concern. J. Mark. Commun. 2017, 25, 421-437. [CrossRef] 
11. Pfeffer, M.J.; Stycos, J.M. Immigrant environmental behaviors in New York City. Soc. Sci. Q. 2002, 83, 64-81. Available online: https://www.jstor.org/stable/42956274 (accessed on 23 October 2020).

12. Suareza, B.C.; Bartond, D.N.; Cimburovad, Z.; Rusche, G.M.; Gomez-Baggethun, E.; Onaindiac, M. Environmental justice and outdoor recreation opportunities: A spatially explicit assessment in Oslo metropolitan area, Norway. Environ. Sci. Policy 2020, 108. [CrossRef]

13. Pearson, A.R.; Ballew, M.T.; Naiman, S.; Schuldt, J.P. Climate change communication in relation to race, class, and gender. Oxf. Res. Encycl. Clim. Sci. 2017. [CrossRef]

14. Iturriza, M.; Hernantes, J.; Abdelgawad, A.A.; Labaka, L. Are cities aware enough? A framework for developing city awareness to climate change. Sustainability 2020, 12, 2168. [CrossRef]

15. Richardson, M.L.; Milton, A.D.; Harrison, E. People with different educational attainment in Washington, DC, USA have differential knowledge and perceptions about environmental issues. Sustainability 2020, 12, 2063. [CrossRef]

16. Schlosberg, D.; Collins, L.B. From environmental to climate justices: Climate change and the discourse of environmental justice. Wires Clim. Chang. 2014. [CrossRef]

17. Theriault, D.; Mowatt, R.A. Both sides now: Transgression and oppression in African Americans' historical relationship with nature. Leis. Sci. 2018. [CrossRef]

18. Malin, S.A.; Ryder, S.; Lyra, M.G. Environmental justice and natural resource extraction: Intersections of power, equity and access. Environ. Sociol. 2019, 5, 109-116. [CrossRef]

19. Parker, J.D.; McDonough, M.H. Environmentalism of African Americans An analysis of the subculture and barriers theories. Environ. Behav. 1999, 31, 155-177. [CrossRef]

20. Bullard, R.D.; Johnson, G.S. Environmental Justice: Grassroots Activism and Its Impact on Public Policy Decision Making. J. Soc. Issues 2000, 56, 555-578. [CrossRef]

21. Mohai, P.; Bryant, B. Is there a "Race" Effect on concern for environmental quality? Public Opin. Q. 1998, 62, 475-505. Available online: https://www.jstor.org/stable/2749675 (accessed on 23 October 2020).

22. Paolisso, M.; Douglas, E.; Enrici, A.; Kirshen, P.; Watson, C.; Ruth, M. Climate change, justice, and adaptation among African American communities in the Chesapeake Bay Region. Weather. Clim. Soc. Am. Meteorol. Soc. 2012, 4. [CrossRef]

23. Teixeira, S.; Zuberi, A. Mapping the racial inequality in place: Using youth perceptions to identify unequal exposure to neighborhood environmental hazards. Int. J. Environ. Res. Public Health 2016, 13, 844. [CrossRef] [PubMed]

24. Ogunbode, C.A.; Arnold, K. A study of environmental awareness and attitudes in Ibadan, Nigeria. Hum. Ecol. Risk Assess. Int. J. 2012, 18, 669-684. [CrossRef]

25. Chen, X.; Peterson, N.N.; Hull, V.; Lu, C.; Lee, G.D.; Hong, D.; Liu, J. Effects of attitudinal and sociodemographic factors on pro-environmental behavior in urban China. Environ. Conserv. 2011. [CrossRef]

26. Fatima, J.K.; Khan, H.Z.; Goh, E. Environmental knowledge and behavioural outcomes of tourism students in Australia: Towards testing a range of mediation and moderated mediation effects. Environ. Educ. Res. 2016, 22, 747-764. [CrossRef]

27. Schulser, T.; Krings, A.; Hernandez, M. Integrating youth participation and ecosocial work: New possibilities to advance environmental and social justice. J. Community Pract. 2019. [CrossRef]

28. Mayer, F.S.; McPherson-Frantz, I. The connectedness to nature scale: A measure of individuals' feeling in community with nature. J. Environ. Psychol. 2004, 24, 503-515. [CrossRef]

29. DC Health Matters. Available online: https://www.dchealthmatters.org/demographicdata (accessed on 23 October 2020).

30. Coon, H.M.; Kemmelmeier, M. Cultural orientations in the United States (re) examining differences among ethnic groups. J. Cross-Cult. Psychol. 2001, 32, 348-364. [CrossRef]

31. Glave, D.D. Rooted in the Earth: Reclaiming the African American Environmental Heritage; Lawrence Hill Books: Chicago, IL, USA, 2010.

32. Smith, K.K. African American Environmental Thought: Foundations; University Press of Kansas: Lawrence, KS, USA, 2007.

33. Travis, R.; Leech TG, J. Empowerment-based positive youth development: A new understanding of healthy development for African American youth. J. Res. Adolesc. 2014, 24, 93-116. [CrossRef] 
34. Reamer, A. Counting for Dollars: The Role of the Decennial Census in the Geographic Distribution of Federal Funds. GW Institute of Public Policy, 17 April 2018. Available online: http://civilrightsdocs.info/pdf/census/ CountingForDollars-Intro.pdf (accessed on 24 October 2020).

35. Amoah, A.; Addoah, T. Does environmental knowledge drive pro-environmental behaviour in developing countries? Evidence from households in Ghana. Environ. Dev. Sustain. 2020. [CrossRef]

36. United States. Government Printing Office. The Kerner Report: The 1968 Report of the National Advisory Commission on Civil Disorders; United States. Government Printing Office: Washington, DC, USA, 1988.

37. Ogbu, J.U. Cultural diversity and human development. New Dir. Child Adolesc. Dev. 1988. [CrossRef]

38. Utsey, S.O.; Bolden, M.A.; Lanier, Y.; Williams, I.I.I. Examining the role of culture-specific coping as a predictor of resilient outcomes in African Americans from high-risk urban communities. J. Black Psychol. 2007, 33, 75-93. [CrossRef]

39. Mikati, I.; Benson, A.F.; Luben, T.J.; Sacks, J.D.; Richmond-Bryant, J. Disparities in distribution of particulate matter emission sources by race and poverty status. Am. J. Public Health 2018, 108, 480-485. [CrossRef] [PubMed]

Publisher's Note: MDPI stays neutral with regard to jurisdictional claims in published maps and institutional affiliations.

(C) 2020 by the authors. Licensee MDPI, Basel, Switzerland. This article is an open access article distributed under the terms and conditions of the Creative Commons Attribution (CC BY) license (http://creativecommons.org/licenses/by/4.0/). 